\title{
Effect of Educational Program About Care of Patients Connected to Extracorporeal Membrane Oxygenation (ECMO) on Nurses Knowledge and Practices
}

\author{
MONA M. SHABAN, M.Sc.; WARDA Y. MOHAMED, D.N.Sc.; AKRAM M. ABD EL-BARY, Ph.D.* and \\ FATMA S. ALI, D.N.Sc.
}

The Department of Critical Care \& Emergency Nursing, Faculty of Nursing, Cairo University and ELSO \& SWAAC**, Egypt

\begin{abstract}
Background: Extracorporeal membrane oxygenation (EC$\mathrm{MO}$ ) or Extracorporeal life support (ECLS) is a technique of providing both cardiac and respiratory support for apatient whose heart and lung are unable to provide an adequate gas exchange to sustain life. Therefore, crtical care nurses should have specific knowledge and practice to provide safe, and efficient care for such group of patients.
\end{abstract}

Aim of Study: This study was carried out to evaluate the effect of ECMO educational program on nurses' knowledge and practices.

Subject and Methods: A quasi-experimental research design was utilized in the current study. Research hypotheses: (1) Critical care nurses who attend the educational program about care of patient connected to ECMO will have a higher post-test mean knowledge scores as compared to their pretest mean knowledge scores all through the assessment times. (2) Critical care nurses who attend the educational program about care of patients connected to ECMO will have a higher post mean practice scores as compared to their pre-test mean practice scores all through the assessment times. A convenience sample of 34 nurses was included in the current study. The study was conducted in a selected Critical Care Department affiliated to Cairo University Hospitals. Three tools were utilized to collect data pertinent to the study: Critical care nurses personal Data sheet; Critical care Nurses' knowledge Questionnaire regarding care of patients connected to ECMO; and Critical Care Nurses' observational check list about care of patient connected to ECMO. The current study revealed that, the majority $(94.1 \%)$ of nurses did not attend any training courses about care of patient connected to ECMO. The two stated research hypotheses were supported indicating significant improvement of critical care nurses knowledge and practices after implementation of ECMO educational program (F-ratio 494.8 at $p \leq 0.0001 * \& 242.204$ at $p \leq .0001$ respectively)

Conclusion: Impementation of a nursing educational program about care of patient connected to ECMO helped in

Correspondence to: Dr. Mona M. Shaban, E-Mail: monamohamed2520@gmail.com assessment and enhancement of nursing knowledge and practices. This will be reflected on critically ill patients' care.

Recommendations: Carrying out in-service training, workshops and continuing educational program a bout ECMO; provision of written guidelines about care of patients on ECMO; and strict observation of nurses practices.

Key Words: Extracorporeal membrane oxygenation (ECMO) - Nurses knowledge and practic.

\section{Introduction}

EXTRACORPOREAL membrane oxygenation (ECMO) is one of the invasive devices. It is a technique of providing both cardiac and respiratory support for patients whose heart and lungs are unable to provide an adequate amount of gas exchange to sustain life [1]. It is used to provide a more advanced assessment and guide therapeutic interventions for critically ill patients where the compxlicity of critical illness increase [2]. As well, ECMO is one of the advanced life support devices. It has become a therapeutic option in acute heart failure or pulmonary hypoxic/hypercapnic failure [3]. This requires specific competencies from the health care team especially critical care nurses. They have to be trained and should have specific knowledge about care of this category of patients to reduce the risk of complications and minimize morbidity [4]

Nursing care of critically ill patients connected to ECMO is challenging because they are unstable and highly dependent [6]. Patients need continuous invasive monitoring, close observation, cardiovascular, respiratory and othe body systems assessment [5]. This is achieved through assessment of vital signs, oxygen saturation, cardiac output, blood gas 
values, urine output and catheters' insertion sites [7]. Nursing care must be directed to reduce risks, prevent associated complications (such as bleeding, cerebral hamorradge, respiratory tract infection, catheter insertion site infection, lower limb ischemia, urinary tract infection, coagulopathy), and provide psychological support for patients and their families [8].

Critically ill patients connected to ECMO includes regular physiotherapy, careful management of devices, management of distress, nutritional support, preventing stress-induced ulceration, venous thrombosis, constipation, pressure ulcers, coagulopathy and cerebral hammorradge [9]. Therefore critical care nurses and doctors have to be trained on using ECMO, and prevent complications [10].

\section{Subjects and Methods}

This study was conducted from April 2016 to August 2017 in Critical Care Department at Cairo University Hospitals.

\section{Significance of the study:}

It has been observed through clinical experience that, patients connected to ECMO develop certain complications. Most of these complications are life threatening although they can be prevented. Therefore critical care nurses' could have a positive role in early detection and prevention of such complication if they are equipped with adequate knowledge and practices regarding care of these patients. Therefore, this study is designed to provide critical care nurses with in-depth information and skills regarding ECMO, its role in treatment of severe cardiopulmonary failure and its life threatening complications. Furthermore, this study could be beneficial in maintaining a cost-effective patient care in the critical care units. It might shorten the hospital stay and protect against many life threatening complications. Also, it is hoped that, this study will generate attention and motivation for further researches in this area. It is expected to help in establishing database about care of patients connected to ECMO.

\section{Research hypothesis:}

To fulfill the aim of this study, the following research hypotheses were formulated:

1- Critical care nurses who attend the educational program about care of patient connected to ECMO will have a higher post-test mean knowledge scores as compared to their pre-test mean knowledge scores all through the assessment times.
2- Critical care nurses who attend the educational program about care of patients connected to ECMO will have a higher post-test mean practice scores as compared to their pre-test mean practice scores all through the assessment times.

\section{Setting:}

This study was conducted in a critical care departement affiliated to Cairo University Hospitals. It consists of 53 beds, 24 beds for Intensive care (ICU), 8 beds for Coronary care (CCU), 2 beds for intermediate care, 10 beds for cardiac catheterization, 4 beds for isolation, 2 beds in shock room which is prepared for the admission of patients supported by ECMO, and 2 beds in patients' assessment room.

\section{Sample:}

Aconvenience sample of 34 nurses working in the selected setting.

\section{Tools of data collection:}

Three tools were developed by the investigator:

Tool (1) - Nurses demographic characteristics data sheet: It covers data such as nurses' age, gender, qualification, years of experience, years of dealing with ECMO patients.

Tool (2) - Critical care nurse's knowledge assessment Questionnaire (pre/post test): It consists of 83 questions covering all basic and general knowledge about ECMO indications, contraindications, complications, initiation and nursing care.

\section{Scoring system:}

One score was allocated for each right answer with a total score of 83 grades. Scores less than $75 \%(<61)$ were considered unsatisfactory knowledge level, and scores more than $75 \%$ (>62) were considered satisfactory.

Tool (3) - Critical care nurses practices observational check: It consists of 168 items classified under two main domins: General care of critically ill patient which consists 61 items about assessment of all body systems (cardiovascular, respiratory, gastrointestinal, genitourinary, central nervous system, and skin), and care of ECMO catheters and the whole circuit which consists of 107 item.

\section{Scoring system:}

Two scores were allocated for each correct and complet intervention with a total of 168 scores. Scores less than $75 \%(<252)$ grades were considered unsatisfactory, and scores more than $75 \%(>252)$ were considered satisfactory. 


\section{Tools validity and reliability:}

Content validity was done to identify the degree to which the used tools measure what was supposed to be measured. Developed tools were examined by a panel of three critical care nursing and two medical experts to determine whether the included items were clear and suitable to achieve the aim of the current study. Five critical care nursin gexperts to determine whether the included items were clear and suitable to achieve the aim of the current study. As well, tools reliability calculated using SPSS with Cronbach's alpha value of 0.79 for nurses knowledge questionnaire and 0.85 for nurses' practice indicating reliability of the developed data collection tool.

\section{Pilot study:}

A pilot study was carried out in April 2016 and conducted on $10 \%$ of the sample (4 nurses) to test for feasibility, and applicability of the data collection tools. Pilot study gave the investigator experience to deal with the included subjects, the research methodology, the data collection instruments, and to estimate the needed time to fill out the data collection sheets. Based on result of the pilot study, needed refinement/modification were done in the data collection sheets and the instructional booklet. Modifications were too few in terms of editing of some sentences, so they did not affect the main data. Therefore, the 4 nurses were included in the actual study.

\section{Protection of human rights:}

An official permission to conduct the study was obtained from the Faculty of nursing research ethical committee and head of the critical care department. Written consents were obtained from nurses who agreed to participate in the study. The investigator emphasized that, participation in this study is absolutely volunteer and each nurse has the right to withdraw from the study at any time without any rational. They were reported that their pre and post test scores will never affect the annual performance. Anonymity and confidentiality of each subject was assured through coding of all data.

Procedure: It was carried out on two phases: Preparatory/designation and implementation/evaluation phases.

\section{Preparatory/designation phase:}

This phase involved preparation and designing of the program plan, data collection tools and the designing of the instructional booklet. As regards preparation of the instructional booklet, it required an extensive review of relevant literature either from textbooks, scientific research articles, web sites searches as well as experts' advices.

The theoretical content of the booklet were concerned with understanding each and every aspect related to ECMO machine, its accessories, definition, configuration, indications and contraindications, complications. The practical part was concerned with nursing management of patients connected to ECMO. The instructional booklet was reviewed by a panel of critical care of medical and nursing experts to ensure validity.

\section{Implementation and evaluation phases:}

The actual data collection started by obtaining nurses' personal charateristics from nurses who agreed to participate in the study using tool (1). Then knowledge was assessed by using tool (2). The theoretical and practical contents were tought for involved nurses through attending the training course. Then knowledge was immediately assessed after implementation of the program, and after 3 and 6 months later to evaluate retention of knowledge. Observation of nurses practice was also carried out immediately after implementing the program and on a daily basesusing tool (3) To assess nursing practices during provision of care. The investigator was available to answer for any question, and provide explanations.

\section{Statistical data analysis:}

Obtained data were scored, tabulated and analyzed utilizing statistical package for social science (SPSS). Version 20. Descriptive as well as inferential statistical were utilized. The level of significance was set at $p \leq 0.05$.

\section{Results}

\section{Demographic characteristics data of the studied} sample:

Table (1) shows that the majority of the studied sample was females (94.1\%), at the age group of $25-45$ years, married $(85.3 \%)$, and had diploma of nursing education (82.4\%). All (100\%) the studied sample did not receive any educational programs about care of patient connected to ECMO, 79.4\% had no experience in dealing with ECMO patients.

Table (2) shows increment in the mean knowledge scores immediately after the program, after 3 , and 6 months with a mean of 94.85, 89.70, and 84.88 respectively. Significant statistical differences were noticed in the mean post test scores as compred to pre test $(\mathrm{F}=494.8, p \leq 0.0001$. So,the first hypothysis can be supported. 
Fig. (1) indicates no significant correlation of age, years of experience, experience in dealing with ECMO patients, educational level and knowledge and practices scores.

Table (3) shows increment of the mean practice scores of the studied sample mmediately after implementation of ECMO program, as compared to after 3 and 6 months, with means of 70.38 , $67.03,63.41$ respectively. So the second research hypothesis can be supported.

Table (1): Percentage distribution of the studied sample as regards demographic characteristics $(n=34)$.

\begin{tabular}{|c|c|c|}
\hline $\begin{array}{l}\text { N \& Percentages } \\
\text { Variable }\end{array}$ & $\mathrm{N}$ & $\%$ \\
\hline $\begin{array}{l}\text { Gender: } \\
\text { Males } \\
\text { Females }\end{array}$ & $\begin{array}{l}2 \\
32\end{array}$ & $\begin{array}{l}5.9 \\
94.1\end{array}$ \\
\hline $\begin{array}{l}\text { Age: } \\
\quad<30 \\
\quad 31-40 \\
\quad>40\end{array}$ & $\begin{array}{l}10 \\
10 \\
14\end{array}$ & $\begin{array}{l}29.4 \\
29.4 \\
41.2\end{array}$ \\
\hline $\begin{array}{l}\text { Marital status: } \\
\text { Single } \\
\text { Married } \\
\text { Divorced }\end{array}$ & $\begin{array}{l}4 \\
29 \\
1\end{array}$ & $\begin{array}{l}11.8 \\
85.3 \\
2.9\end{array}$ \\
\hline $\begin{array}{l}\underset{<5}{\text { Years of experience: }} \\
5-10 \\
>10\end{array}$ & $\begin{array}{l}6 \\
7 \\
21\end{array}$ & $\begin{array}{l}17.6 \\
20.6 \\
61.8\end{array}$ \\
\hline $\begin{array}{l}\text { Experience in dealing } \\
\text { with ECMO patient: } \\
\text { Yes } \\
\text { No }\end{array}$ & $\begin{array}{l}7 \\
27\end{array}$ & $\begin{array}{l}20.6 \\
79.4\end{array}$ \\
\hline $\begin{array}{l}\text { Educational level: } \\
\text { Secondary school diploma } \\
\text { Technical nursing institute } \\
\text { Bachelor degree }\end{array}$ & $\begin{array}{l}28 \\
4 \\
2\end{array}$ & $\begin{array}{l}82.4 \\
11.8 \\
5.9\end{array}$ \\
\hline $\begin{array}{l}\text { Attended ECMO Training courses: } \\
\quad \text { No } \\
\text { Yes }\end{array}$ & $\begin{array}{l}34 \\
0\end{array}$ & $\begin{array}{l}100.0 \\
0\end{array}$ \\
\hline
\end{tabular}

Table (2): Comparison of total mean knowledge scores in the three assessment times $(\mathrm{N}=34)$.

\begin{tabular}{llcc}
\hline \multirow{2}{*}{ Times } & \multicolumn{2}{c}{ Knowledge } & \multirow{2}{*}{ F \& $p$} \\
\cline { 2 - 3 } & Mean & SD & \\
\hline Pre-Test & 35.09 & 13.27 & \multirow{2}{*}{$494.8 / 0.0001^{*}$} \\
Immediate Post & 94.85 & 3.30 & \\
After 3 months & 89.70 & 3.45 & \\
After 6 months & 84.88 & 3.09 & \\
\hline
\end{tabular}

*Significant, $p^{<}-0.0001$

Table (3): Comparison of total mean practice scores in the three assessment times $(\mathrm{N}=34)$.

\begin{tabular}{llll}
\hline \multirow{2}{*}{ Times } & \multicolumn{2}{c}{ Practice } & \multirow{2}{*}{ F \& $p$} \\
\cline { 2 - 3 } & Mean & SD & \\
\hline Pre-Test & 26.26 & 3.40 & \\
Immediate Post & 70.38 & 9.10 & $242.2 / 0.0001 *$ \\
After 3 months & 67.03 & 8.67 & \\
After 6 months & 63.41 & 8.20 & \\
\hline *Significant, $p^{<} \_0.0001$ & & &
\end{tabular}
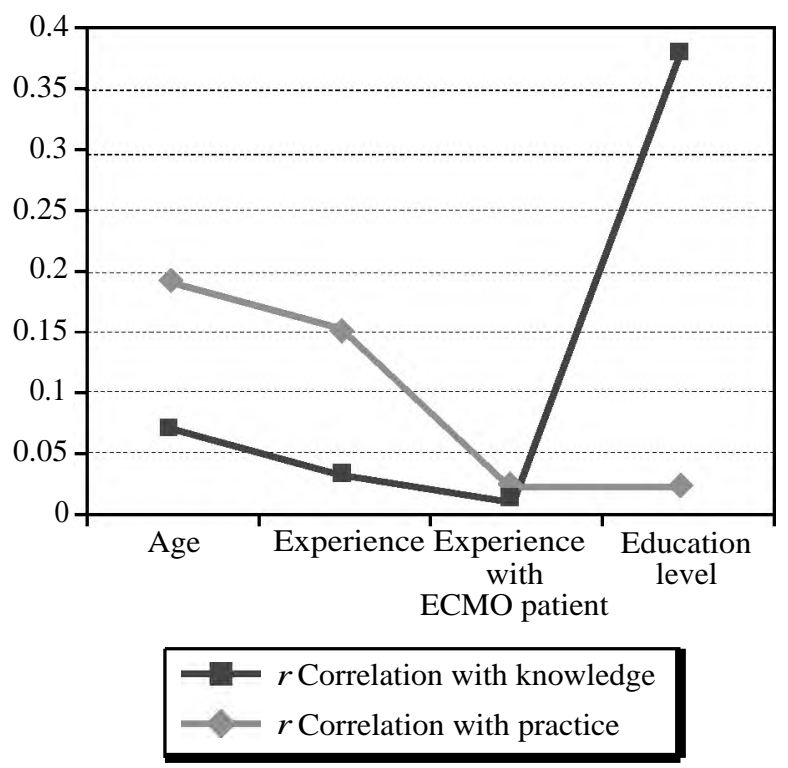

Fig. (1): Correlation between demographic data, knowledge and practice scores $(\mathrm{N}=34)$.

\section{Discussion}

The current study revealed the dominance of adult, married, females, diploma nurses who had limited experience in dealing with critically ill patient connected to ECMO. They didn't attend any continuing educational courses about care of patient connected to ECMO. The dominance of diploma nurses "from the investigator's point of view" could be attributed to the traditional nursing educational system in Egypt, which emphasise the importance of enhancing their knowledge and practice.

Carrying out the current study started with assessment of critical care nurses knowledge regarding care of patient connected to ECMO. It revealed that, the studied sample had significant improvement in their knowledge scores immediately after implementation of the educational program as compared to their knowledge scores before implementing the program regarding definition, indications, contraindications, complications of ECMO, with significant statistical differences in mean scores. The practical part included assessment of nurses actions regarding care of cannula and the whole circuit. Critical care nurses in the current study nurses rerevealed satisfactory level of practice regarding care of catheters and the whole circuit with significant statistical difference in practice scores in all assessment times. This finding is in agreement with that of Go-Woon Kim, Younsuck Koh, Chae-Man Lim, [11] who revealed improvement of critical care nurses experience after imple- 
menting a training program about ECMO. Enhancement of nurses knowledge and practices "from the investigator's point" is expected to be reflected on patients'. So the two stated research hypotheses are supported.

The current study revealed significant statistical differences in mean knowledge scores regarding complications associated with ECMO after implementation of program as compared to before. As well, the studied sample ahowed a satisfactory practice regarding care of patients connected to ECMO. These findings are in agreement with that of Jones-Akhtarekhavari [12] who studied the development of a successful ECMO program, and showed that increased experience or familiarity with ECMO management increased the chance of patients' survival and reduced potential complications.

More specifically, assessing nurses knowledge about mechanical complication associated with ECMO, in the current study revealed a significant statistical difference in the mean knowledge scores regarding ECMO complications after implimentation of ECMO program as compared to before. This finding is in agreement with that of JonesAkhtarekhavari [13] who showed increased experience or familiarity with ECMO management, and revealed increased the chance of patient survival and reducing potential complications. From "the investigator point of view" enhancement of nursing staff knowledge is expected to be reflected on the patient care and prevent suspected complications.

The current study demonstrate that, the majority of the studied sample provided satisfactory levels and high post-test total mean knowledge scores after implementation and attending ECMO program as compared to the first assessment scores. A significant statistical difference was found in mean knowledge scores after implementing the ECMO educational program as compared to before. This could support the first and research hypothesis, which states, critical care nurses who attend the educational program about ECMO will have a higher post-test total mean knowledge scores as compared to the first assessment (pre-test) score.

As well, the present study indicated improvement in nurses practice after implementing the program as compred to before, with a significant statistical difference in the mean practice scores. This finding is in agreement with that of Tonna, Selzman, Smith \& Youngquist [14], who conducted a study about development and implementation of a comprehensive, multidisciplinary emergency department ECMO program for nurses to improve their knowledge and practice and showed that the program was successful and nurses provided a high level of nursing care and intervention to ECMO patient.

Also, the present study findings are in agreement with that of Cavarocchi, Wallace, Hong, Tropea, Byrne, Pitcher, \& Hirose [14] who carried out a study to improve nurses knowledge and practice about care for ECMO patients and decrease the cost of care. The study revealed success of the program for nurses in maintaining patients' safety and improving outcomes. As well, Chiu, [16] carried out a study in Queen Mary hospital, Hong Kong which aimed to establish a nurse led simulationbased ECMO educational program for 45 intensive care nurses to evaluate and imrove their competencies regarding care of patients on ECMO. The study showed that, nurses were lacking knowledge about looking after and dealing with critically ill patients connected to ECMO (the pre test scores were $47.5 \%$ as compared to $90 \%$ in the post-test). As well, the program proved that it helped in providing a safer clinical ECMO service and better patient outcomes.

The current study revealed no significant statistical correlation between demographic data (years of experience and educational level), of the studied sample and knowledge scores. This finding is in agreement with that of Taha and Ali [15], who conduct a study about the impact of a training program on critical care nurses 'knowledge and practice regarding physical restrains and reported that nurses' qualification, and years of experience had no influence on practice scores. This finding is not consistent with that of Thomas [18], who conducted a study to evaluate the effectiveness of video assisted teaching program on knowledge and practice regarding cardio version and defibrillation and revealed a high significant statistical association between practices scores and work experience.

Thus the first research hypothesis, which states, that critical care nurses who attend the educational program about care of patients connected to ECMO will have a higher post total mean knowledge scores as compared to pre-test. Thus, improvement of critical care nurses and knowledge "from the investigator point of view" will be reflected in patient care. It is expected to increase critically ill patients' survival rate and prevent suspected complications.

Thus, the second research hypothesis, which states, that critical care nurses who attend the 
educational program about care of patients connected to ECMO will have a higher post total mean practice scores as compared to pre-test. Thus, improvement of critical care nurses pactices "from the investigator point of view" will be reflected in patient care. It is expected to increase critically ill patients' survival rate and prevent suspected complications.

\section{Conclusion:}

Based on finding of the current study, it can be concluded that, continuous assessment and enhancement of nursing knowledge and practices play an important role in management of critically ill patients. Critical care nurses assigned to care for patients connected to ECMO showed adequate knowledge and practice regarding care of critically $1 l$ patients after implimenting the educational program. The programe showed significant improvement in nurses' knowledge and practices.

\section{Recommendations:}

Continuing in-service training and workshops should be conducted for nurses to improve their knowknowledge and practices; Nursing curriculum must cover the theoretical and practical sessions care about care of patients connected to ECMO; Continuous assessment and observation of nurses' practipractices to identify areas of weaknesses in caring for patients connected to ECMO; Provision of critic of critical care nurses with illustrated guidelines about assessment and nursing management of paabout care of patient connected to ECMO; Replication of the study on a large probability sampsample from different geographic locations in Egypt; and carrying study to evaluate the effof effect of educational program on patients' outcomes.

\section{References}

1- PATRONITI N. and PESENTI A.: ECMO-Extracorporeal life support in Adults F. Sangalli 1st (Ed.). Springer, 2014

2- ANNICH: ECMO: Extracorporeal Cardiopulmonary Support in critical care 4 th, (Ed.). Extracorporeal Life Support Organization, 2014.

3- RICH P.B., SCHREINER R.J., HIRSCHL R.B. and BARTLET R.H.: Extracorporeal Life. Support for Adult Patient with Sever Respiratory Failure, 2015.

4- ANNICH: ECMO: Extracorporeal Cardiopulmonary Support in critical care. $1 \mathrm{st}$, (Ed.). Extracorporeal lIfe Support Organization. 5-Kolla S., Awad, S.S., 2016.
5- WAGNER K.D., HARDIN-PEARCE M.P.G., BRENNER Z.R. and KRENZER M.: High-acuity Nursing. 6 th edition. Upper Saddle River, New Jersey: Pearson, c2014. Illustrations (Chiefly Color), 28cm, 2014.

6- MARASCO S.F., LUKAS G., MCDONALD M., MCMILLAN J. and IHLE B.: Review of ECMO (extra corporeal membrane oxygenation) support in critically ill adult patients. Heart, Lung and Circulation, 17: S41-S47, 2008.

7- PATRONITI N. and PESENTI A.: ECMO - Extracorporeal life support in Adults F. Sangalli 1 st (Ed.). Springer, 2014.

8- PEDEN MATHEW L., CONRAD STEVEN A., RYCUS PETER T. and THIAGARAJAN RAVI R.: Extracorporeal Life Suport Organization registery international report ASAIO Journal, 2017.

9- BARTLET R.H.: "Physiology of Extracorporeal Life cardiopulmonary Support in critical care second edition, J.B. Zwischenberger et al, editors. Extracorporeal life support organization 41-66 2000.

10- GO-WOON KIM, YOUNSUCK KOH, CHAE-MAN LIM, JIN WON HUH, SUNG HO JUNG, JOON BUM KIM and SANG-BUM HONG: The effect of an improvement of experience and training in extracorporeal membrane oxygenation management on clinical outcomes, 2011.

11- KIM G.W., KOH Y., LIM C.M., HUH J.W., JUNG S.H., KIM J.B. and HONG S.B.: The effect of an improvement of experience and training in extracorporeal membrane oxygenation management on clinical outcomes. The Korean Journal of Internal Medicine, 33 (1): 121, 2018.

12- JONES-AKHTAREKHAVARI J., TRIBBLE T.A. and ZWISCHENBERGER J.B.: Developing an extracorporeal membrane oxygenation program. Critical Care Clinics, 33 (4): 767-775, 2017.

13- TONNA J.E., SELZMAN C.H., MALLIN M.P., SMITH B.R., YOUNGQUIST S.T., KOLIOPOULOU A. and FAIR J.F.: Development and implementation of a comprehensive, multidisciplinary emergency department extracorporeal membrane oxygenation program. Annals of Emergency Medicine, 70 (1): 32-40, 2017.

14- CAVAROCCHI N.C., WALLACE S., HONG E.Y., TROPEA A., BYRNE J., PITCHER H.T. and HIROSE H.: A cost-reducing extracorporeal membrane oxygenation (ECMO) program model: A single institution experience. Perfusion, 30 (2): 148-153, 2015.

15- TAHA N.M. and ALI Z.H.: Physical Restraints in Critical Care Units: Impact of a Training Program on Nurses' Knowledge and Practice and on Patients' Outcomes. J. Nurs. Care., 2 (2): 2167-1168, 2013.

16- THOMAS M.P.: A study to evaluate the effectiveness of video assisted teaching programme on knowledge and practice regarding cardioversion and defibrillation among staff nurses working in cardiac unit in selected hospitals of Bagalkot Doctoral dissertation, 2013. 


\section{تأثير برنامج تعليمى عن رعاية المرضى المتصلين بجهاز أكسجة الدمام الدمام

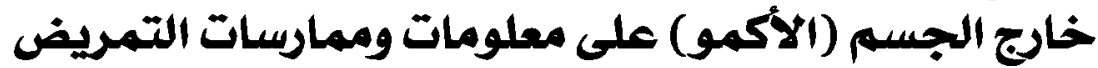

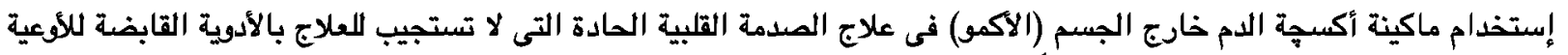

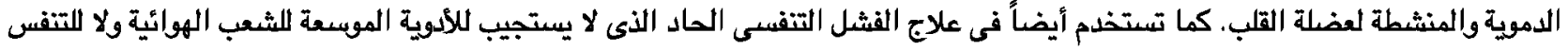

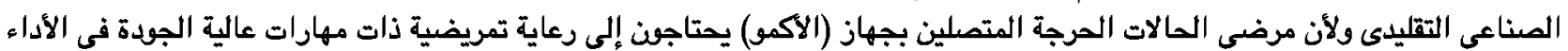

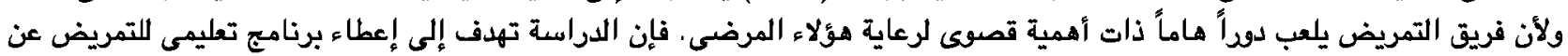

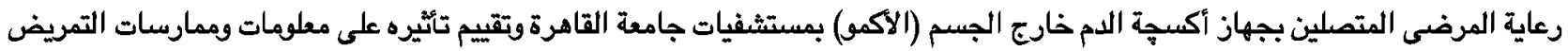

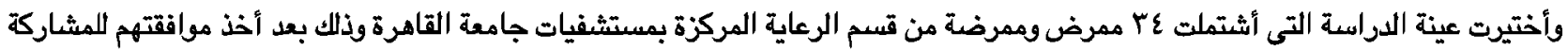

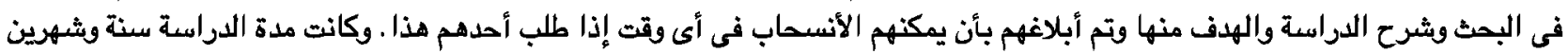

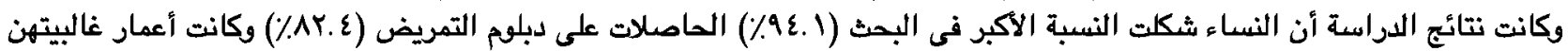

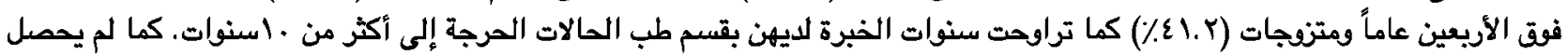

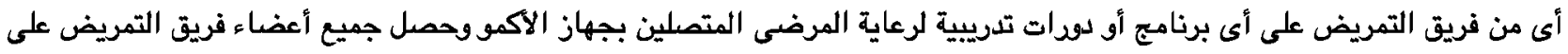

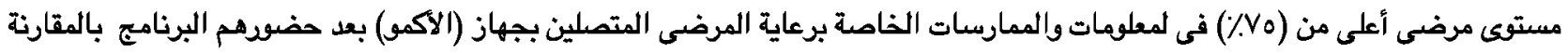

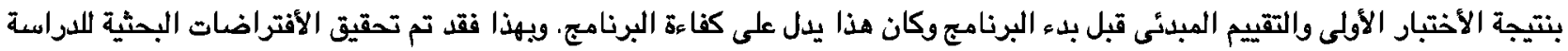

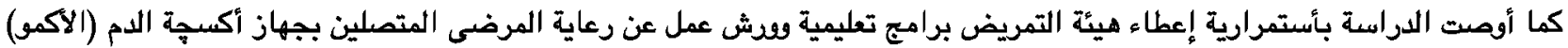
لتحقيق الكفاءة والجودة فى الأداء. 